\title{
Curva de Phillips: os casos de Brasil e EUA, de 1999-08
}

\author{
Rodolfo de Oliveira Lopes ${ }^{1}$ \\ Douglas Alcantara Alencar ${ }^{2}$
}

\begin{abstract}
Resumo: O presente trabalho tem como objetivo avaliar se a curva de Phillips é valida para o Brasil e EUA no curto prazo. Dessa forma, pretendemos contribuir para o debate sobre a validade dos instrumentos de política Monetária, objeto de grande debate em as diversas teorias econômicas. Após uma avaliação teórica do contexto econômico num mundo pós-mercantilismo e suas consequentes vicissitudes até a etapa atual, o presente trabalho buscou em diversas fontes as origens dessas mudanças e o porquê das trocas de paradigmas econômicos. Observou-se que tais mudanças foram originadas pela dificuldade do modelo em questão de explicar o contexto econômico à época, mais especificamente, a dificuldade de se diagnosticar os ciclos econômicos. Foi realizado uma modelagem macroeconométrica para verificar a eficácia de políticas monetárias de ambos os bancos centrais no período verificado. Os resultados mostraram que houve um aumento de fato da credibilidade do $\mathrm{BCB}$, a possibilidade de um objetivo em sua agenda: inflação dentro da meta. Concluiu-se que, por mais que o BCB tenha uma postura austera, explorando o trade-off inflação/ desemprego da curva expectacional de curto prazo de Phillips, ele não é conivente com o aumento do desemprego, mas sempre trabalhando dentro dos limites das metas para a inflação. Para o caso americano, concluiu-se também o objetivo na agenda do FED, ressaltando sua maior aversão (com relação ao BCB) a um baixo nível de atividade econômica. No entanto, a política sistematicamente laxista da autoridade monetária realmente minimizou os efeitos de crises inicias, porém, a persistência de tais políticas trouxeram uma taxa de juros exacerbadamente baixa e perda da eficácia de sua política monetária (via taxa de juros), destarte, para lidar com o fenômeno da crise atual, houve necessidade de emissão de papel moeda em escala jamais vista. Dessa forma concluímos que a curva de Phillips de curto prazo, tanto para o Brasil quando para os Estados Unidos é valida ao menos no curto prazo, o que pode corroborar as hipóteses das teorias monetaristas, assim como as teorias das rigidezes dos salários para o caso da teoria novo-keynesiana.
\end{abstract}

\footnotetext{
1 Economista na empresa TAM Linhas Aéreas. Mestrando em economia pela USP-ESALQ. 
Palavras-chave: política monetária, curva de Phillips de curto prazo, teoria macroeconômica.

JEL: E31, E37

\title{
Phillips curve: the cases of Brazil and USA from 1999-08
}

\begin{abstract}
This study aims to evaluate whether the Phillips curve is valid for the USA and Brazil in the short term. Thus, we intend to contribute to the debate on the validity of the instruments of monetary policy, the subject of much debate in the various economic theories. After a theoretical evaluation of the economic context in a post-mercantilism and its attendant vicissitudes until the current step, the present study aimed to various sources the origins of these changes and why the exchange of economic paradigms. It was observed that these changes were caused by the difficulty of the model in question to explain the economic context at the time, specifically, the difficulty in diagnosing the economic cycles. The macroeconometric modeling was conducted to verify the effectiveness of monetary policies of both central banks in the period observed. The results showed that there was indeed an increase of the credibility of the Central Bank of Brazil, the possibility of an objective in your agenda: inflation within the target. It was concluded that, even though the Central Bank of Brazil has an attitude austere, exploring the trade-off inflation / unemployment curve Phillips short term, it is not complicit with the rise in unemployment, but always working within the limits of inflation targeting. For the U.S. case, it was also aimed at FED schedule, highlighting its greater aversion (with respect to the Central Bank of Brazil) to a low level of economic activity. However, the policy systematically lax monetary authority actually minimized the effects of initial crisis, however, the persistence of such policies brought an interest rate exaggeratedly low and loss of efficacy of monetary policy (via interest rates), Thus, for deal with the phenomenon of the current crisis, it was necessary to issue paper currency in an unprecedented scale. Thus we conclude that the Phillips curve short term, both for Brazil to the United States when it is valid at least in the short term, which may corroborate the hypothesis of monetarist theories, as well as theories of wage rigidities for the case new-Keynesian theory.
\end{abstract}

Key-words: monetary policy, Phillips curve short-term, macroeconomic theory.

JEL: E31, E37 


\section{Introdução}

O presente trabalho tem como objetivo avaliar se a curva de Phillips é valida para o Brasil e EUA no curto prazo. Dessa forma, pretendemos contribuir para o debate sobre a validade dos instrumentos de política monetária, objeto de grande debate entre as diversas teorias econômicas. $\mathrm{O}$ trabalho está dividido da seguinte forma: na primeira seção desse trabalho aborda a histórica discussão a respeito da neutralidade da moeda, assim como, as reformulações de políticas econômicas, passando por diferentes escolas (escola neoclássica pré-keynesiana, keynesiana, etc.) e por diferentes paradigmas econômicos. A segunda seção foca o contexto econômico de Brasil e EUA no ano de 1999-2008, pois, como se verificará adiante, é nesse período que se estabelecerá uma análise econométrica para ambos os países. Já na terceira seção, vamos abordar a metodologia do modelo formal utilizado. O modelo de vetores auto-regressivos (doravante VAR) permite - como se verificará em pormenores neste capítulo - avaliar a eficácia de políticas monetárias para o caso brasileiro e americano. A base de dados escolhida foi de 1999 até 2008 trimestralmente. A opção por esse período se deve a estabilidade econômica brasileira atingida, bem como, o início do regime de câmbio flutuante. As variáveis selecionadas foram: desemprego, inflação e juros. Finalmente na última seção, avaliou-se - como explicado acima - a eficácia de políticas monetárias via modelagem VAR, assim sendo, podem-se observar como as três variáveis do modelo se comportam diante de choques hipotéticos. Far-se-á importante nesta seção, realizar a junção do contexto econômico do período com as funções de resposta ao impulso do modelo VAR. E finalmente a ultima subseção de comentários finais.

\section{Aspectos Dinâmicos de Teoria Econômica}

Seguindo os pressupostos da escola neoclássica (a qual tem como os principais expoentes Alfred Marshall e Arthur Pigou) e também a novo-clássica (Robert Lucas e Thomas Sargent), a neutralidade da moeda se verifica, pois ela é vista basicamente como facilitadora das necessidades transacionais dos agentes econômicos, ou seja, seguindo o postulado, ela serve única e exclusivamente como meio de troca e jamais como um instrumento de prelúdio para o desenvolvimento econômico (ou ainda, como um ferramental anticíclico - uma discussão que será retomada adiante); ainda na mesma matiz de pensamento, afirmavam que variáveis reais não seriam influenciadas por variáveis nominais - a qual a moeda pertence - pois ações do governo eventualmente poderiam não ser críveis e ainda esconder determinadas facetas, no entanto, apenas fatores reais poderiam modificar variáveis econômicas reais de longo prazo, 
tais como produção e emprego.

Vista pela ótica keynesiana, a moeda assume características opostas, já que a neutralidade da moeda não se verifica no curto e nem no longo prazo. Keynes, como não se desaveio com a moeda, tratou de lhe dar significativa importância na determinação do emprego e produção no conjunto do sistema econômico (DILLARD, 1993). Para ele, a moeda sairia do campo meramente transacional, e assim numa espécie de relaxamento da hipótese neoclássica, assumiria três funções: i-) a de meio de troca; ii-) a de unidade de conta e ; iii-) a de reserva de valor. Dentro dessas três funções, é irretorquível que Keynes caracteriza a função de acumular valor como sendo a mais importante, como pode ser visto:

\begin{abstract}
A psicologia super-racionalista dos economistas clássicos induz a uma interpretação falsa do comportamento no mercado de inversão, e não leva em conta o papel estratégico do dinheiro como elo protetor entre o presente e o futuro incerto. Pois, como vimos, a incerteza do futuro que torna aventuroso o investimento real, empresta também encanto ao dinheiro como reserva de valor. (KEYNES, 1936, p. 222).
\end{abstract}

\title{
1.1. As reformulações de políticas econômicas
}

Os teóricos de economia antes da experiência da Grande Depressão 1929, que abalou os países desenvolvidos da época, se diferenciavam basicamente em aspectos microeconômicos, fato o qual, levou Keynes a acomodar todos os economistas que escreveram citeriormente a 1936 - que pensavam até então de forma homogênea no que tange a macroeconomia - como pertencentes à mesma classe, o que o levou a tratar todos de maneira indiscriminada (FROYEN, 2003). Com o advento da crise de 1929, Keynes rompe com o modelo o qual se educou, dando ênfase agora ao papel da demanda agregada via política fiscal - para estimular a economia (DILLARD, 1993). Em síntese, a teoria de Keynes quebra com o que havia sido escrito até então, e enfatiza o uso da primazia da política fiscal frente à política monetária, pois esta só serviria para se adequar ao montante de política fiscal realizado, para elevar o nível de demanda agregada e assim levar a economia a patamares superiores de emprego (SICSÚ, 1996).

\subsubsection{A política econômica do mercantilismo à Grande- Depressão de 1929}

A ortodoxia econômica que vigorava antes do advento da crise de 1929 era 
a da escola neoclássica, a qual tinha como principais características: i-) livre flexibilidade de preços; ii-) microfundamentos; iii-) validade da "lei de Say" e da dicotomia neoclássica; e iv-) modelo de longo prazo.

A primeira característica do modelo neoclássico pré-keynesiano ${ }^{1}$ salientado acima, diz respeito a livre flexibilidade dos preços, pressuposto o qual garante à economia um processo de auto-ajuste, como indicador de abundância e escassez de produtos:

Os gêneros de primeira necessidade são muito mais intensamente afetados em seu preço pela variação de sua quantidade do que os regalos da vida. Se a colheita de cereal for 1/3 menor do que seu volume habitual, ou, ainda, se o suprimento de cereal no mercado, provindo da produção interna ou da importação, for cortado na mesma medida, isso criará uma elevação muito maior do que $1 / 3$ no preço do cereal. Não é uma previsão inverossímil dizer que seu custo mais do que duplicará devido à deficiência de 1/3 ou 1/4 no suprimento (JEVONS, 1983, p. 99).

A segunda característica do modelo é a questão da fundamentação microeconômica da macroeconomia, conceito já trabalhado pelos clássicos e "neoclássicos" (Smith, Jevons, Walras, entre outros), em que o papel do agente egoísta e otimizador - enfatizado na figura do homo economicus seria de vital importância para o bom funcionamento da economia de um país, destarte, se todos agissem da mesma maneira, a "mão invisível" do mercado se responsabilizaria em atingir o equilíbrio macroeconômico (SMITH, 1776).

A terceira hipótese do modelo, valida a "lei de Say" e também a dicotomia neoclássica. A "lei de Say", sugere que tudo que for produzido será integralmente demandado, assim, percebe-se que jamais poderia ocorrer crises de superprodução. O último termo que caracteriza a economia neoclássica, diz respeito ao seu caráter de longo prazo. Essa qualidade pode ser verificada em sua função de produção:

$$
Y=f(K, N)
$$

Em que:

$Y=$ produto

$K=$ estoque de capital da economia (planta e maquinaria)

$N=$ trabalho.

Essa função (1) revela que apenas "K" e "N" podem influenciar o nível de produto, em que "K" é fixo no curto prazo. Assim, apenas uma mudança "tecnológica" em " $K$ " pode causar um aumento no produto² (e por isso também é chamado de modelo de oferta, pois enfatiza somente o papel da oferta como 1 Como os principais contribuidores podem-se destacar: A. Marshall e A. C. Pigou.

2 Um aumento na mão-de-obra também ocasionaria um aumento no produto, mas como visto, uma das hipóteses do modelo é que só há desemprego voluntário. 
determinante - de variáveis reais - do sistema econômico), ou seja, isso só acontecerá no longo prazo ${ }^{3}$.

Esses fundamentos formam um corpo de postulados o qual regeu a política econômica num mundo pré-recessão da década de 30. Assim, pode-se concluir que esse modelo liberal ${ }^{4}$ não é consentâneo com a intervenção estatal no sistema econômico, pois essa intervenção acabaria por expulsar na mesma magnitude o setor privado da economia (via aumento da taxa de juros real) num fenômeno que ficou conhecido como crawding out (BLANCHARD, 2011).

\subsubsection{O mundo se torna "keynesiano"}

O cenário econômico em que Keynes escreve a Teoria Geral não era nada animador, visto que a atividade econômica entrou em um declínio em extensão e gravidade sem precedentes na época, em que a taxa de desemprego nos EUA subiu de 3,2\% da força de trabalho, em 1929, para 25,2\% da força de trabalho, em 1933 (FROYEN, 2003). Destarte, a teoria keynesiana desenvolveu-se tendo como pano de fundo a crise de 1929.

Como feito para o modelo neoclássico na seção anterior, agrupar-se-ão os principais pontos das idéias de Keynes e uma rápida explicação se dará ulteriormente. Dillard (1993) reuniu os principais fundamentos da teoria de Keynes ao redor dos seguintes pontos: i-) o caráter geral de sua teoria; ii-) o papel da moeda; iii-) a relação entre os juro e a moeda; iv-) o investimento; e v-) a incerteza acerca do futuro.

Como visto anteriormente, a teoria (neo) clássica se limita ao caso especial de pleno emprego, paradoxalmente Keynes explica “o que é” que determina o volume de emprego em um momento dado, seja o pleno emprego ou qualquer outro nível de emprego, daí o caráter geral de sua teoria (DILLARD, 1993).

A segunda característica do modelo de Keynes diz respeito ao papel da moeda na economia (tópico tratado na seção de neutralidade versus nãoneutralidade), em que ela não assume mais uma postura passiva, pois para Keynes só se guarda riqueza na forma de dinheiro quando o futuro econômico é incerto (DILLARD, 1993). Como pode ser visto em uma passagem de seu livro:

A posse de dinheiro efetivo mitiga nossa inquietação, e o prêmio que exigimos para nos desprender de nosso dinheiro é a medida de nosso grau de inquietação (KEYNES, 1936, p. 216).

3 Para os clássicos, a função de demanda seria apenas a de indicar o nível de preços de equilíbrio. 4 A origem do liberalismo é atribuída a Adam Smith, o qual cedeu posteriormente matéria-prima para os economistas da escola neoclássica. 
O terceiro fundamento ressalta o juro como prêmio por não entesourar, Dillard (1993), argumenta que a taxa de juros depende da intensidade do desejo de se entesourar dinheiro, ou do que Keynes retrata como a "preferência à liquidez" para fins especulativos.

A quarta característica é a do investimento como o mais importante fator determinante de emprego. Para Keynes, o consumo era fundamentalmente um dispêndio induzido que só dependia do nível de renda (isso não implicava que os gastos com consumo não poderiam variar ao longo do tempo), assim procurou pelos componentes autônomos da demanda agregada que eram determinados, em sua majoritária parte, independentemente da renda corrente. Quando ocorria uma variação desses dispêndios autônomos, a renda variava. Portanto, Keynes considerava que o investimento era o componente autônomo da demanda agregada que exibia maior variância. Ele acreditava que essas variações nos dispêndios autônomos por parte dos investimentos eram os principais responsáveis pela instabilidade da renda (FROYEN, 2003). Entretanto, o desemprego é resultado do investimento exíguo, em que o emprego nas atividades de inversão colabora para manter a procura da produção existente de bens de consumo (DILLARD, 1993). Keynes afirma que, em nossa sociedade, com sua desigualdade característica na distribuição de renda, seria impossível ter inversão de capital suficiente para manter em funcionamento as fábricas antigas. Para ele, o emprego oscila, antes de qualquer coisa, porque oscila o investimento. Para explicar esse fato, Keynes cunha o termo Propensão Marginal a Consumir (PMgC); em que, a PMgC de um camponês, por exemplo, será sempre maior que a de um banqueiro ${ }^{5}$ (o que naturalmente leva a um acúmulo de recursos ociosos).

E por último, Keynes destaca a incerteza acerca do futuro, enfatizado por ele na forma de "a irracionalidade psicológica como causa da instabilidade". Como o mercado de inversão é produção de bens não destinados ao consumo imediato, pode-se afirmar que está relacionado com o futuro de maneira direta (DILLARD, 1993).

Como pode ser verificado pela breve explanação do modelo proposto por Keynes nesta seção, ele rompeu com a escola (neo) clássica, e plasmou para o mundo suas teorias, moldadas resumidamente num papel agora relevante da política fiscal e monetária. Esse movimento ficou conhecido na literatura como: "A revolução keynesiana". Esse modelo fez com que o mundo retornasse ao rumo da prosperidade, fazendo com que os anos 1950 a 1970 ficassem conhecidos na Europa como "os anos gloriosos" e nos EUA como "o boom econômico". No entanto, esse postulado se revelou inconsistente ao longo do tempo, pois na década de 1970, o mundo foi acometido por uma inflação 
ascendente e concomitante desemprego, além de uma crise fiscal agravada ${ }^{6}$.

Assim sendo, os ciclos econômicos foram responsáveis por mudanças na forma de pensar em economia, como explanado até aqui, a ortodoxia clássica foi substituída pela "heterodoxia" keynesiana e esta, como de forma irretorquível, não sobreviveu às flutuações dos ciclos econômicos. Entretanto, o que se pode observar, é que essas duas escolas foram arraigadas na teoria econômica e são responsáveis até hoje por fornecer material para se conhecer economia e/ou explicar os ciclos econômicos, visto que todas as outras escolas que surgiram a partir da década de 1970, tinham como base, a escola (neo) clássica ou a keynesiana, como se verá adiante.

\subsubsection{Neokeynesiasnos, novos-clássicos e novos-keynesianos}

Posto os modelos neoclássico e keynesiano nas seções anteriores, cabe a esta seção tratar de escolas que surgiram no pós-guerra - neokeynesianos, novos-clássicos e novos-keynesianos - que são nada mais que variações de postulados neoclássicos e/ou keynesianos7 ${ }^{7}$

O período 1950 - 1980 fora conhecido como o welfare state $^{8}$, em que o capitalismo após superar a grande tragédia humana da segunda guerra mundial entrou numa rota de crescimento, visto que o mundo cresceu a uma taxa média de $4 \%$ ao ano, via forte intervenção estatal, e com avanços tecnológicos, eficiência jamais vista nas empresas, novidades nas telecomunicações e transportes, entre outros (AMORIM, 2002). Não obstante, uma crise estava por vir e mudar "novamente" o paradigma econômico. Uma crise no balanço de pagamentos americana e juntamente com perda de competitividade de sua indústria, fizeram com que os EUA optassem pelo regime de câmbio flutuante e conseqüente ruptura com o acordo de Bretton Woods. As conseqüências dessas medidas não foram àquelas esperadas pelo governo americano, fato o qual, levou Paul Volcker (presidente do FED à época) a implementar a "diplomacia do dólar forte" via elevadas taxas de juros (AMORIM, 2002). Os choque do petróleo (1973 e 1979) e concomitante juros altos (ressaltando que a política de elevação dos juros americana se espraiou para as demais economias), fizeram com que as dívidas de alguns países emergentes que contraíram dívidas externas a juros pós-fixado se elevassem abruptamente e, por conseguinte, trazendo instabilidade macroeconômica 6 Para se compreender os desdobramentos dos acontecimentos na década de 1970 para o caso brasileiro, ver: Veloso, J., P., A fantasia política: a nova alternativa de interpretação do II PND, Revista de Economia Política, vol. 18, n ${ }^{\circ} 2$ (70), abril-junho/1998. Para se entender o ocorrido com o mundo à época, ver: Krugman, P., e Obstfeld, M., Economia Internacional: Teoria e Política.

7 Omodelo exposto na seção 1.2.2, parte de pressupostos estritamente escritos por John Maynard Keynes em sua General theory (1936) e também de seu trabalho anterior Treatise on Money (1930), e não de corolários oriundos de seus escritos que se intitularam "keynesianos".

8 Esse período foi caracterizado por um forte crescimento soviético e um capitalismo "moribundo"; assim, com o espectro soviético à frente, o capitalismo inegavelmente tinha que mostrar sinais de crescimento. Sendo assim, pode-se caracterizar o welfare state como um mix entre visão econômica (políticas keynesianas) e visão política ("ameaça” soviética). Ver Robério Paulino: Socialismo no século XX: o que deu errado? 2008. 
a esses países. Bem assim, houve necessidade de mais uma modificação no paradigma econômico que prevalecia à época e uma nova onda resgatando os conceitos da tradição clássica foi implementada, era o início da nova era liberal capitaneada por Reagan (EUA) e Tatcher (Inglaterra).

Os neokeynesianos tinham plena dominância do debate econômico no período pós-guerra (principalmente nos anos 1960), essa corrente compartilhava de alguns dos pressupostos de Keynes e ressaltava que o mercado tinha falhas e suas conseqüências eram prejudiciais às nações, bem assim, a intervenção estatal era bem vista e atuando na direção oposta ao problema, poderia corrigir tais falhas e guiar a economia rumo ao crescimento e a estabilidade (AMORIM, 2002). De maneira geral, a escola keynesiana ortodoxa pode ser destinguida por alguns itens, como: (a) a economia é inerentemente instável, e está sujeita a choques aleatórios, esses choques são atribuídos a mudanças na eficiência margial do investimento, seguida de uma mudança no estado de confiança dos negócios por parte dos empresarios; (b) a economia não volta para o equilíbrio rapidamente, e mais que isso, a economia não se auto-equilíbra; (c) os níveis da oferta agregada e do emprego são essencialmente determinados pela demanda agregada, sendo assim, as autoridades podem intervir em relação ao emprego eficientemente influenciando o nível da demanda agregada, e; (d) em relação a estabilização econômica é preferível a utilização da política fiscal em detrimento da política monetária, pois a primeira é considerada mais eficiente (SNOWDON; VANE. P. 102, 2005). O instrumental utilizado pelos neokeynesianos era basicamente o modelo IS-LM de Hansen e Hicks ${ }^{9}$ que ficou conhecido na literatura como síntese neoclássica (ou neokeynesiana); e para a determinação dos preços, optou pela curva de Philips (1958), a qual contextualizava uma relação inversa entre inflação e desemprego. Assim, haveria possibilidade em optar-se por um ponto de "equilíbrio" entre inflação e desemprego. Entretanto, os neokeynesianos não conseguiram explicar a estagflação ${ }^{10}$ no final dos anos 1970.

É assim que surge no final da década de 1970 a escola novo-clássica, valendo-se do individualismo metodológico clássico, princípio de market clearing $^{11}$ e uma nova ferramenta, as expectativas racionais. O princípio de expectativas racionais sugere que, haveria uma relação entre os preços esperados e os preços efetivos (contrariando os fundamentos das expectativas adaptativas, que só ressalta o papel dos preços passados) e o indivíduo sendo racional maximizaria suas atividades financeiras via escolha intertemporal (SIMONSEN, 1995). Destarte, a escola novo-clássica atraiu uma grande legião de economistas no final da década de 1970 - que estavam atônitos por não conseguirem explicar os problemas de sua época - visto que apesar de propor um modelo que converge ao equilíbrio, ela foi capaz de elucidar algumas

9 Há uma certa confusão na literatura, a qual afirma que o modelo IS-LM é um modelo keynesiano, cabe ressaltar aqui que esse modelo é uma síntese neoclássica, e não estritamente keynesiano. 10 Fenômeno caracterizado por recessão e inflação simultaneamente. 11 A expressão market clearing refere-se à não-formação de estoques indesejados, ou seja, é uma conseqüência da "lei de Say". 
ausentes respostas para as flutuações econômicas, pois variações no produto só ocorreriam em razão de erros expectacionais (AMORIM, 2002). Essas variações oriundas de choques inesperados teriam respostas em variáveis reais apenas no curto prazo (e consequente retorno no longo prazo), pois se os eventos futuros fossem antecipados pelos agentes, o fato só seria verificado em variáveis nominais (preço, por exemplo), e variáveis reais permaneceriam estáveis (ZETTEL, 2006).

No entanto, a escola novo-clássica enfraqueceu-se em detrimento de algumas críticas ressaltadas por um novo grupo (heterogêneo) de economistas, os novos-keynesianos. Entre as críticas podem-se destacar: a escola só tratava (à lá neoclássicos) do desemprego voluntário e friccional, foi mal-sucedida econometricamente e ao demonstrarem que não adiantava intervir na economia, arrefeceu-se rapidamente sua agenda de pesquisa (AMORIM, 2002). É nesse ambiente que surgem os novos-keynesianos, que numa tentativa de resgatar o modelo neokeynesiano, reafirmam os objetivos da escola antiga e excluindo os pontos falhos da teoria criticados pelos novos-clássicos. Os novos-keynesianos não promoveram grandes mudanças nos paradigmas econômicos, na verdade, eles se valeram de muitos procedimentos utilizados pelos novos-clássicos. Realçaram o papel da microeconomia para explicar variações macroeconômicas, e através do individualismo metodológico assumiram preços e salários rígidos para baixo (ZETTEL, 2006). Logo, se existem rigidez no sistema de preços e no mercado de trabalho, qualquer mudança que viesse a ocorrer no PIB nominal, significaria uma mudança em variáveis reais, ou seja, na produção. Sendo assim, os novos-keynesianos utilizam-se desse argumento para justificar o papel do Estado na economia, que foi uma volta em aspectos teóricos aos neokeynesianos (AMORIM, 2002).

\section{Avaliação de políticas econômicas no Brasil e nos EUA de 1999 a 2008}

Na presente seção, far-se-á um exercício retrospectivo de políticas econômicas vinculadas para os casos de Brasil e Estados Unidos, respectivamente. O período analisado foi o de 1999 até 2008. Há uma razão do retrospecto ser nesse período, pois é o mesmo que fornecerá a base de dados para o estudo econométrico que se verificará na seção 4. A escolha desse período está relacionada ao processo de estabilização da economia brasileira, visto que, se o período utilizado fosse maior (desde os planos de estabilização ou mesmo o período de âncora cambial, por exemplo) a modelagem econômica ficaria comprometida. Entretanto, é de vital importância entender o contexto econômico à época para o caso de ambos os países; após esse exercício, o que se verificará na seção 4 (a seção 3 fornecerá a metodologia do modelo formal 
utilizado) é a eficácia de políticas econômicas, para tanto, utilizar-se-á o modelo econométrico denominado vetores auto-regressivos (VAR).

\subsection{Transumância monetária no Brasil}

O regime monetário precedente ao de metas para a inflação ${ }^{12}$ foi marcado pelo seu término em janeiro de 1999, o qual foi submetido a uma crise cambial pondo fim ao processo de implementação do Plano Real (caracterizado inicialmente pela indexação ao dólar) e assim instaurando-se um novo período de consolidação da estabilidade da nova moeda. Outrossim, esse novo regime, o de metas para a inflação, tinha como principais elementos: o anúncio explícito de uma meta para a inflação, comprometimento com a estabilidade de preços como sendo o principal objetivo de longo prazo da política monetária, transparência ao conduzir a política monetária e determinação de uma "razoável" autonomia ${ }^{13}$ ao Banco Central (MODENESI, 2005).

Segundo Modenesi (2005), o Banco Central simplesmente negligenciou um dos mais controversos debates da história do pensamento econômico: que a discussão em torno da eficácia (ou não) da política monetária (discussão tratada na seção 1). Assim sendo, a neutralidade da moeda foi meramente postulada pelo Banco Central, a qual foi atribuída como principal causa da implementação do regime de metas para a inflação.

O posicionamento teórico do BCB é fundamentado por meio de um modelo específico, o novo-clássico, o qual adota um conjunto de hipóteses que não são aceitas unanimemente pela comunidade acadêmica. Bem assim, ignorouse a contribuição de diversas outras escolas, mais especificadamente a de autores de orientação keynesiana ${ }^{14}$, os quais negam a neutralidade da moeda no longo prazo. A posição do BCB representa o mainstream do pensamento econômico na atualidade, que não revela nenhuma espécie de consenso entre os economistas, fato o qual dá a entender os relatórios de inflação dessa instituição (MODENESI, 2005).

No entanto, cabe ressaltar alguns dos principais resultados que deram ao Brasil uma credibilidade maior tanto no cenário interno quanto no externo via prática de políticas ortodoxas (uma corroboração disso pode ser visto na seção 4, em que há diminuição da inflação em resposta de um aumento da taxa de juros). Essas políticas trouxeram para o Banco Central do Brasil grande prestígio no restante do mundo, e pode-se caracterizá-las como sendo uma política econômica sólida, ancorada no regime de metas para a inflação, com a manutenção do regime de câmbio flutuante, com a construção de elevados superávits primários e também com a obtenção de elevadas $12 \mathrm{O}$ ano de 1999 foi de transição do regime de metas cambiais para o regime de metas para a inflação. Ver: Economia Monetária e Financeira; teoria e prática/Carvalho, F. [et al.] - Rio de Janeiro; Campus, 2000. 13 O Banco Central só tem autonomia para seguir a meta estipulada pelo Conselho Monetário Nacional (CMN), caso ele tivesse liberdade para decidir também sobre o objetivo a ser seguido, ele seria independente. Ver: Blinder, Central Banks: theory and practice (1998)

$14 \mathrm{O}$ debate entre as escolas foi explanado na seção 2. 
reservas internacionais. Ressalvando que a crítica do parágrafo anterior de Modenesi, foi uma crítica de caráter ideológico e não técnico, portanto, podese afirmar (com o privilégio da visão ex post) que a política adotada pelo $\mathrm{BCB}$ expurgou o principal problema que inviabilizava o crescimento econômico - a inflação - e trouxe o Brasil para um patamar superior de "confiança" para com outros países (e também a almejada estabilidade macroeconômica), e sua conseqüente corroboração veio com o "grau de investimento" agraciado ao Brasil com a agência de classificação de risco S\&P no ano de 2008.

$\mathrm{E}$ ainda, retornando um pouco às críticas disparadas ao presidente do $\mathrm{BCB}$ (Gustavo Franco) pela demora na flexibilização cambial no ano de 1999, é de bom tom ressaltar que, se o câmbio fosse desvalorizado abruptamente (como argumentavam seus críticos) aumentaria estrondosamente tanto a dívida pública quanto a dívida do setor privado (pois ainda não se havia feito o hedge necessário). Além do mais, como ressalta Blinder (1998), uma política de estabilização bem-sucedida baseada em golpes preventivos parecerá equivocada e pode conseqüentemente expor o Banco Central a uma série de críticas pesadas (verificar-se-á na seção 4 que, golpes preventivos de política monetária e conseqüente arrefecimento posterior do mesmo não "prejudicará" a economia por muito tempo, visto que há uma elasticidade fortemente decrescente da própria taxa de juros até o segundo mês da aplicação da política). A razão irretorquível é simples, pois se a autoridade monetária contrai sua política tão cedo que a inflação nunca suba, caracterizando um sucesso estrondoso da política, poderá acontecer de céticos para com a política do Banco Central questionarem, o porquê da prevenção se o "dragão" da inflação era visível em nenhum lugar.

Ficou claro, diante da argumentação exposta que, o BCB atua de acordo como uma economia se comportando como a dos novos-clássicos. Portanto, se as expectativas são racionais, as pessoas entendem o padrão de comportamento do Banco Central e a política monetária não consegue produzir diferenças sistemáticas entre a inflação efetiva e esperada. Destarte, sabe-se que um Banco Central que regularmente se atenha aos ganhos de curto prazo irá, na média, produzir mais inflação, mas não um volume maior de emprego do que um BC mais resoluto (BLINDER, 1998). A credibilidade da autoridade monetária foi de vital importância para o FED e para BCB (em épocas distintas); pois em 1982-1983, quando o FED - sob o comando de Paul Volcker - abandonou o monetarismo e sem sinalizar ao mercado que estava abandonando o combate à inflação (pelo contrário, a tônica da política monetária era contê-la), conseguiu uma transição entre as políticas muito bem sucedida em razão de sua credibilidade na luta contra a inflação (conquistada a duras penas). $\mathrm{O}$ mesmo se aplica ao caso brasileiro no ano de 1999, com o abandono da meta cambial para a implementação do regime de metas; não demora a perceber que, sem credibilidade essa transição em hipótese alguma seria bem sucedida.

2.2. $O$ contexto econômico americano 
A política econômica americana dos anos 1990 para cá foi marcada por um interessante mix de políticas. Como pode ser verificado em Deos e Andrade (2006), houve nesse período uma interessante interação entre as políticas fiscal e monetária, acarretando na entrada em uma rota de crescimento com baixa inflação e equilíbrio fiscal. O ponto fundamental dessa política foi à adoção de uma política monetária acomodatícia, que contrabalançou a execução de uma política fiscal contracionista (a política ficou conhecida como Clinton-Greenspan). Tal mix entre as políticas monetária e fiscal acabou por se constituir em um importante marco para a história de políticas econômicas para os Estados Unidos.

Ainda na mesma linha de pensamento, a economia americana utilizou nos anos 1992-93 e 2000-2002 dos mesmos princípios de prática econômica, fazendo com que a economia dos EUA superasse rapidamente baixas momentâneas na atividade econômica. Para Deos e Andrade (2006), a saída da recessão e a forte recuperação da economia americana nesses dois períodos, podem ser atribuídas, a uma política monetária tipicamente compensatória. A principal característica desta política é a capacidade de ação rápida e imediata por parte da autoridade monetária em resposta a conjunturas adversas. Esse fenômeno só pode acontecer, segundo os autores, em situações em que prevalece o uso de políticas discricionárias inteligentes e habilidosas. Em razão desse fenômeno, pode-se afirmar que a experiência americana de política monetária a partir dos anos 1990 foi caracterizada como um exemplo de política monetária bem sucedida (DEOS e ANDRADE, 2006). Durante esse período, todas essas superações da economia americana diante de conjunturas econômicas adversas (além da pequena crise nos anos 1990, lembra-se também que os anos 2000-2002 foram marcados pelo estouro da "bolha" na bolsa de valores e pelos ataques às torres gêmeas em nova Iorque) foram realmente anuladas pela discricionariedade na política monetária via derrubada da taxa de juros. Esse fenômeno pode ser verificado no trabalho econométrico da seção 4, em que se pode perceber a aversão do FED em relação ao desemprego, visto sua elasticidade negativa na taxa de juros (a discussão será retomada na seção de choques macroeconômicos). Não obstante, com visão apriorística ${ }^{15}$ a respeito da atual crise financeira, o que se pode afirmar é que a política laxista por parte do FED durante a "era Greenspan" tem grande responsabilidade pela grande destruição de riquezas que estamos presenciando nos últimos meses.

Sicsú (2002), afirma que não há evidencias de conceder ao Banco Central americano a tarefa única de alcançar uma meta para a inflação. Pois o FED tem explicitamente dois objetivos, manter a estabilidade de preços (sem qualquer meta previamente fixada) e buscar o pleno emprego, visto que ninguém pode negar que os Estados Unidos obteve os maiores sucessos econômicos a partir da década de 1990. Para o autor, as evidências são inconclusivas em relação à adoção do regime de metas.

15Apriorística por se tratar de uma literatura ainda escassa no que tange ao fenômeno da atual crise financeira desencadeada pelo setor imobiliário americano, mais especificadamente às hipotecas de alto risco, conhecidas no mercado financeiro como sub-prime. 
No ano de 2005, o FED enviou ao congresso americano o Federal Reserve's Monetary Policy Report, documento o qual suscitou controvérsias entre os economistas. Como pode-se perceber em Deos e Andrade (2006), o relatório trouxe um evento novo, pois ressaltava projeções de crescimento do produto, da taxa de desemprego e da taxa de inflação não só para o ano de 2005, mas também para o ano seguinte.

Assim sendo, ficou claro o impasse dentro do FOMC (Federal Open Market Comitee) a respeito da adoção do regime de metas. Deos e Andrade (2006), afirma que o próprio chairman do FED, Alan Greenspan foi contra a iniciativa, pois para ele, o argumento básico é que a estabilidade de preços mantida a níveis baixos pelos países que até agora aderiram ao regime de metas não pode ser atribuída, exclusivamente, ao regime de metas para a inflação. E ainda, as regras são por natureza muito simples e a realidade econômica é caracterizada por complexidade e mudança.

Cabe ainda ressalvar que, há uma grande diferença entre o histórico de inflação entre as diversas nações, assim, fica claro que uma política econômica aplicada com êxito por um país não signifique que será também bem sucedida em outro. Um fato análogo pode ser verificado em Farhi (2007), em que mostra as diferentes formas de classificar os países no tocante à implementação do regime de metas, assim seguindo um critério adotado por economistas do FMI (Fundo Monetário Internacional), pode-se destacar um grupo de países o qual os EUA se encaixam denominado "ecletic inflation targeters" (EIT); grupo caracterizado por países que obtêm tamanha credibilidade que conseguem manter uma estabilidade de preços a níveis baixos sem precisar se comprometer de forma inequívoca com o regime de metas. Pode-se dizer que esses países são aqueles que emitem moeda conversível e instrumento de reserva internacional. Estão nesse grupo os EUA e os países da zona do euro, assinalando que ambos os Bancos Centrais (FED e BCE) negam que tenham adotado o regime de metas.

\section{Metodologia}

Nesta seção, far-se-á uma rápida explicação do modelo de vetores auto-regressivos, à luz do referencial teórico, será realizada uma análise positiva de variáveis macroeconômicas, tais como, desemprego, inflação e juros. A metodologia de vetores auto-regressivos se justifica dado que estamos interessados na curva de Phillis de curto prazo. Para trabalhos futuros, pode ser interessante verificar a validade da curva de Phillips de longo prazo, e para isso, seria mais apropriado utilizar o modelo com a metodologia de Vetor de Correção dos Erros (VEC). Os países analisados serão Brasil e Estados Unidos, como explicado anteriormente. Destarte, o modelo proporcionará uma verificação 
de respostas (a choques hipotéticos) de variáveis macroeconômicas e conseqüentemente poder-se-á verificar a corroboração da relação entre inflação e desemprego no curto prazo como advogam os novos-keynezianos e monetaristas. Para tanto, utilizaremos a metodologia dos Vetores auto-regressivos, que como em Vartanian (2008), a principal vantagem do modelo VAR é a possibilidade de estimar diversas variáveis simultaneamente, evitando, desse modo, os problemas de identificação dos parâmetros em modelos de equações simultâneas. Desse modo, o modelo permite analisar as conseqüências de mudanças de políticas econômicas de forma satisfatória. Antes de aplicar a abordagem do modelo VAR e extrair informação do modelo são necessários alguns testes, como: testes de raiz unitária, seleção do número de defasagens do modelo, teste de exogeneidade das variáveis - VAR Granger Causality/ Block Exogeneity Wald Tests, raízes inversas do polinômio característico auto-regressivo e função de resposta ao impulso.

\subsection{Vetores auto-regressivos}

Aqui, o intuito é explanar brevemente sobre o modelo VAR. O surgimento do modelo de vetores auto-regressivos (CHRISTOPHER, 1980; GUJARATI, 2003) sucedeu-se de um problema ocasionado no modelo de equações simultâneas, pois antes de estimar tais modelos, é preciso ter certeza de que as equações no sistema são identificadas, e para tanto, é freqüentemente obtida supondo que algumas variáveis predeterminadas (exógenas mais endógenas defasadas) estão presente somente em algumas equações. Diante disso, os modelos de equações simultâneas foram seriamente criticados por Sims (1980).

Como em Vartanian (2008), a principal vantagem do modelo VAR é a possibilidade de estimar diversas variáveis simultaneamente, evitando, desse modo, os problemas de identificação dos parâmetros em modelos de equações simultâneas. Desse modo, o modelo permite analisar as conseqüências de mudanças de políticas econômicas de forma satisfatória.

\subsection{Modelo VAR: forma algébrica}

Segue-se a forma algébrica de um modelo VAR de ordem superior:

$$
y_{t}=A_{1} y_{t-1}+\ldots+A_{n} y_{t-N}+B x+\varepsilon_{t}
$$

Em que:

$y_{t}=$ vetor de variável endógena. 
$x_{t}=$ vetor de variável exógena.

$A_{1}+\ldots+A N$ e $B=$ matrizes dos coeficientes a serem estimados.

$\varepsilon_{t}=$ vetor de inovações auto-correlacionado.

Desse modo, em um sistema tridimensional com apenas uma defasagem, com as variáveis $\mathrm{x}, \mathrm{y}, \mathrm{z}$, o modelo consegue estimar coeficientes de três equações sob o formato:

$$
\begin{aligned}
& x_{t}=\alpha+\beta_{0} x_{t-1}+\beta_{1} y_{t-1}+\beta_{2} z_{t-1} \\
& y_{t}=\alpha+\beta_{0} x_{t-1}+\beta_{1} y_{t-1}+\beta_{2} z_{t-1} \\
& z_{t}=\alpha+\beta_{0} x_{t-1}+\beta_{1} y_{t-1}+\beta_{2} z_{t-1}
\end{aligned}
$$

Em que $x, y$ e $z$ são as variáveis dependentes no período t, $\alpha$ é constante e $\beta_{0}, \beta_{1}$ e $\beta_{2}$ são parâmetros de inclinação das equações 2,3 , e 4 . As variáveis explicativas do modelo são as variáveis defasadas. No instante $t-1$, as variáveis assumem características de independência, ao passo que no instante $t$, agora assumem a propriedade de variáveis explicativas.

Essa é a principal característica de um modelo VAR, ou seja, as variáveis explicadas do sistema, também o são pelo próprio passado.

\section{3•3. Variáveis utilizadas}

As três variáveis utilizadas no modelo - desemprego, inflação e juros - foram coletadas de modo que, tanto o período inicial, janeiro de 1999, como o final, dezembro de 2008, são iguais para os dois países analisados. Os dados utilizados na estimativa foram extraídos do Macrodados 7.0 e do Instituto Brasileiro de Geografia e Estatística (IBGE), com periodicidade mensal.

As descrições das variáveis utilizadas foram as seguintes: íses, em porcentagem ao ano;

i-) desemprego: taxa de desemprego mensal da economia nos 2 pa-

ii-) inflação: referem-se aos índices de preços ao consumidor nos dois países (ressaltando que nos EUA, foi utilizado o cpi less food and energy que é o usualmente verificado e no Brasil o índice de preços ao consumidor amplo) em número-índice base 100 (dezembro de 2003) e;

iii-) taxa de juros: taxa de juros de curto prazo da economia, em porcentagem ao ano. 


\section{Choques macroeconômicos hipotéticos no Brasil \\ e nos EUA}

Após a implementação do Plano Real, o Brasil viveu um processo de estabilização macroeconômica. O período anterior ao plano foi caracterizado por cenários econômicos turbulentos que por diversas vezes na tentativa de estabilizar a economia, os planos acabaram tendo resultados não satisfatórios. Outrossim, esta seção tem por objetivo analisar as variáveis macroeconômicas do Brasil no período em que a estabilidade já estava garantida, e para a análise do modelo VAR não resultar viesada, o período escolhido foi a partir de 1999, o qual teve fim a âncora cambial, até 2008. O mesmo período e as mesmas variáveis (desemprego, inflação e juros) são análogos ao caso americano, onde também haverá uma interpretação das funções de resposta ao impulso.

Depois de realizado o teste de raiz unitária em nível, observou-se que as três variáveis (desemprego, inflação e juros) eram não estacionárias, o que compromete a estabilidade do modelo. Portanto foi feita a diferenciação das séries, ou seja, realizou-se a primeira diferença do logaritmo para todas as variáveis. Destarte, efetuou-se o teste de Dickey-Fuller Aumentado para as três variáveis, o resultado pode ser visto na Tabela 1.

TABELA 1. TESTE DE RAIZ UNITÁRIA DICKEY-FULLER AUMENTADO $(\mathrm{ADF})$

Null Hypotesis: D (Desemprego) has a unit root

Exogenous: Constant, Linear Trend

Lag Length: 0 (Automatic based on SIC, MAXLAG =10)

\begin{tabular}{lc}
\hline Augmented Dickey-Fuller test statistic & t-Statistic \\
\hline Test critical values: & -10.433 .520 \\
$1 \%$ level & \\
$5 \%$ level & -4.037 .668 \\
$10 \%$ level & -3.448 .348 \\
\hline
\end{tabular}

Fonte: Elaboração própria de acordo com cálculos realizados no pacote econométrico Eviews 5.0. 
TABELA 1 (Continuação). TESTE DE RAIZ UNITÁRIA DICKEY-FULLER AUMENTADO (ADF)

Null Hypothesis: D(IPC) has a unit root

Exogenous: Constant, Linear Trend

Lag Length: o (Automatic based on SIC, MAXLAG=10)

\begin{tabular}{ll}
\hline & t-Statistic \\
Augmented Dickey-Fuller test statistic & -5.009 .791 \\
\hline Test critical values: & \\
$1 \%$ level & -4.037 .668 \\
$5 \%$ level & -3.448 .348 \\
$10 \%$ level & -3.149 .326 \\
\hline
\end{tabular}

Null Hypothesis: D(JUROS) has a unit root

Exogenous: Constant, Linear Trend

Lag Length: 2 (Automatic based on SIC, MAXLAG = 10)

t-Statistic

Augmented Dickey-Fuller test statistic

$-6.425 .187$

Test critical values:

$1 \%$ level $-4.039 .075$

$5 \%$ level

$10 \%$ level

$-3.149 .720$

Fonte: Elaboração própria de acordo com cálculos realizados no pacote econométrico Eviews 5.0.

Na figura 1, podem-se observar as séries em nível e diferenciadas. A figura é representada pelas três variáveis, a linha vermelha mostra a série em nível e a linha azul a série diferenciada.

Para se determinar o número de defasagens do modelo, houve a necessidade de se recorrer a diversos critérios, resultados os quais são apresentadas na Tabela 2. Atenta-se aqui a um fato relevante, pois três critérios apontaram nove defasagens e dois indicaram uma defasagem, contudo, foi utilizada apenas uma defasagem - nove defasagens resultaram em um modelo sem convergência e com grandes oscilações - portanto, obteve-se um modelo VAR(1). $\mathrm{O}$ asterisco ao lado do número indica a melhor defasagem de acordo com cada teste. 
FIGURA 1. VARIÁVEIS EM NÍVEL E EM PRIMEIRA DIFERENÇA
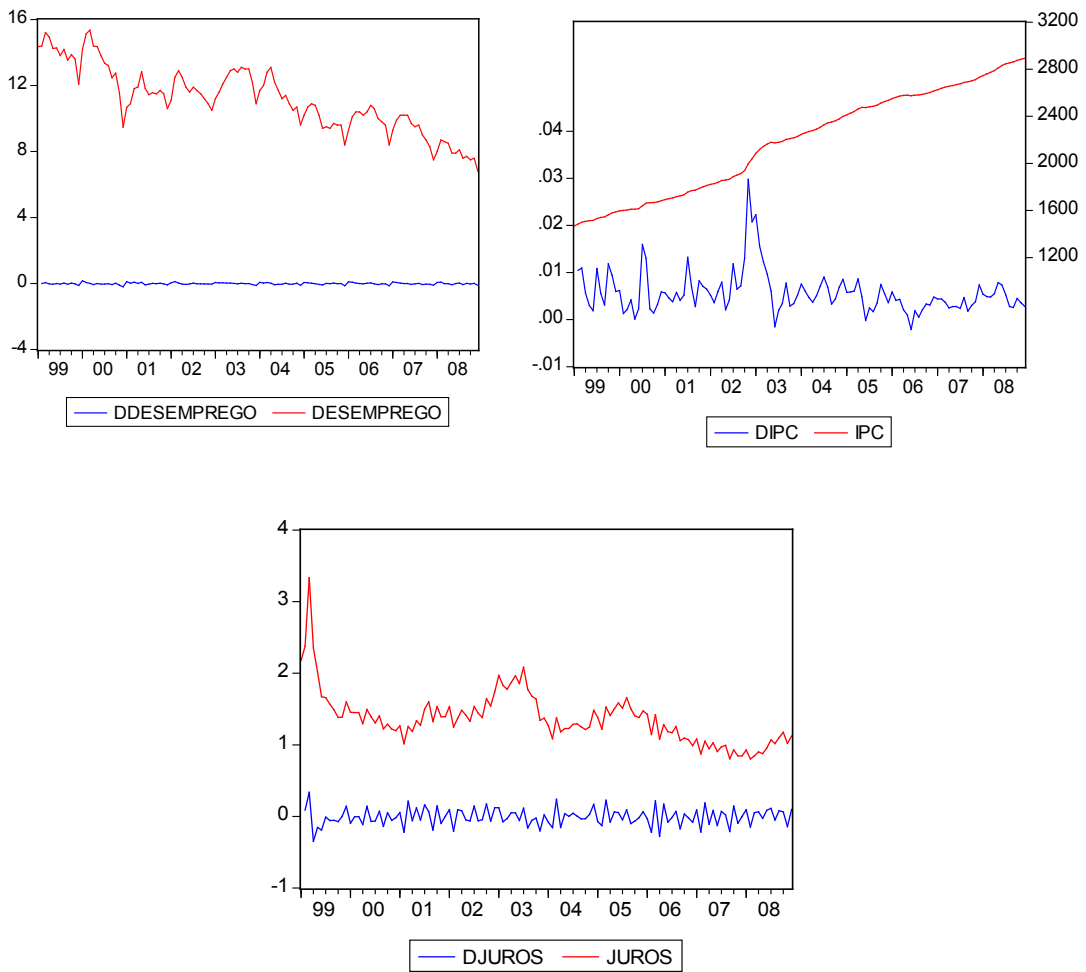

Fonte: Elaboração própria com base no pacote econométrico Eviews 5.0.

TABELA 2. SELEÇÃO DO NÚMERO DE DEFASAGENS DO MODELO

\begin{tabular}{lllllll}
\hline Lag & LogL & LR & FPE & AIC & SC & HQ \\
\hline o & 672.389 & NA & $9.30 \mathrm{e}-10$ & -12.2823 & -12.2083 & -12.2523 \\
1 & 731.720 & 114.308 & $3.69 \mathrm{e}-10$ & -13.2059 & $12.9096^{*}$ & $13.0857^{*}$ \\
2 & 744.394 & 23.7197 & $3.45 \mathrm{e}-10$ & -13.2733 & -12.7548 & -13.0630 \\
3 & 755.621 & 20.3932 & $3.32 \mathrm{e}-10$ & -13.3142 & -12.5734 & -13.0137 \\
\hline
\end{tabular}

NOTA: * indicates lag order selected by the criterion.

LR: sequential modified LR test statistic (each test at $5 \%$ level).

FPE: Final prediction error.

AIC: Akaike information criterion.

SC: Schwarz information criterion.

HQ: Hannan-Quinn information criterion.

Fonte: Elaboração própria com base no pacote econométrico Eviews 5.o. 
TABELA 2 (Continuação). SELEÇÃO DO NÚMERO DE DEFASAGENS DO MODELO

\begin{tabular}{lllllll}
\hline Lag & $\operatorname{LogL}$ & LR & FPE & AIC & SC & HQ \\
\hline 4 & 762.614 & 12.3179 & $3.45 \mathrm{e}-10$ & -13.2773 & -12.3144 & -12.8868 \\
5 & 768.951 & 10.8135 & $3.63 \mathrm{e}-10$ & -13.2285 & -12.0433 & -12.7478 \\
6 & 780.834 & 19.6240 & $3.46 \mathrm{e}-10$ & -13.2814 & -11.8739 & -12.7106 \\
7 & 792.439 & 18.5251 & $3.32 \mathrm{e}-10$ & -13.3292 & -11.6996 & -12.6683 \\
8 & 812.942 & 31.6013 & $2.71 \mathrm{e}-10$ & -13.5402 & -11.6884 & -12.7893 \\
9 & 826.688 & $20.4299^{*}$ & $2.51 \mathrm{e}-10^{*}$ & $13.6273^{*}$ & -11.5533 & -12.7862 \\
10 & 832.229 & 7.92976 & $2.71 \mathrm{e}-10$ & -13.5638 & -11.2675 & -12.6326 \\
\hline
\end{tabular}

NOTA: * indicates lag order selected by the criterion.

LR: sequential modified LR test statistic (each test at $5 \%$ level).

FPE: Final prediction error.

AIC: Akaike information criterion.

SC: Schwarz information criterion.

HQ: Hannan-Quinn information criterion.

Fonte: Elaboração própria com base no pacote econométrico Eviews 5.o.

Como o ordenamento das variáveis é de vital importância para o modelo VAR, executou-se o teste de exogeneidade das variáveis VAR Granger/Block Exogeneity Wald Tests. De acordo com a estatística $\chi^{2}$, as variáveis devem ser ordenadas da mais exógena para a mais endógena. O resultado é ilustrado na Tabela 3. Portanto, o ordenamento das variáveis segue do seguinte modo: desemprego, inflação e juros.

TABELA 3. TESTE DE EXOGENEIDADE DAS VARIÁVEIS - VAR GRANGER CAUSALITY/BLOCK EXOGENEITY WALD TESTS

\begin{tabular}{llll}
\hline Dependente Variable: & DDESEMPREGO & & \\
\hline Excluded & Chi-sq & df & Prob. \\
DIPC & 1.021039 & 1 & 0.3123 \\
DJUROS & 0.488701 & 1 & 0.4845 \\
All & 1.834858 & 2 & 0.3995 \\
\hline
\end{tabular}

Dependent variable: DIPC

Fonte: Elaboração própria com base nos cálculos do pacoteeconométrico Eviews 5.0. 
TABELA 3 (Continuação). TESTE DE EXOGENEIDADE DAS VARIÁVEIS - VAR GRANGER CAUSALITY/BLOCK EXOGENEITY WALD TESTS

\begin{tabular}{llll}
\hline Excluded & Chi-sq & df & Prob. \\
DDESEMPREGO & 2.836427 & 1 & 0.0921 \\
DJUROS & 0.299319 & 1 & 0.5843 \\
All & 3.181491 & 2 & 0.2038 \\
\hline \multicolumn{4}{c}{ Dependent variable: DJUROS } \\
\hline Excluded & Chi-sq & df & Prob. \\
\hline DDESEMPREGO & 4.502498 & 1 & 0.0338 \\
DIPC & 5.262926 & 1 & 0.0218 \\
All & 9.465469 & 2 & 0.0088 \\
\hline
\end{tabular}

Fonte: Elaboração própria com base nos cálculos do pacote econométrico Eviews 5.0.

Para o modelo VAR ser estacionário, há necessidade de estacionariedade nas séries. Assim sendo, a Figura 2 mostra a estabilidade do modelo pela análise das raízes inversas do polinômio característico auto-regressivo. Como o modelo tem três variáveis e testes anteriores indicam uma defasagem como sendo uma boa opção, observa-se que as três raízes encontram-se no interior do círculo unitário, fato o qual caracteriza um modelo estável.

As funções de resposta ao impulso são dadas na Figura 3, ela nos mostra o comportamento da economia brasileira diante de um choque hipotético em cada uma das variáveis. As funções de resposta ao impulso é análise essencial para a interpretação do modelo VAR. Para a realização do modelo, o período verificado foi entre janeiro de 1999 a dezembro de 2008, como explicado anteriormente (e também explicado na seção 2, incluindo uma interpretação da conjuntura no período). Cada coluna contém choques realizados por uma mesma variável e suas conseqüentes respostas nas demais variáveis (incluindo a própria variável). 
FIGURA 2. RAÍZES INVERSAS DO POLINÔMIO CARACTERÍSTICO AUTOREGRESSIVO

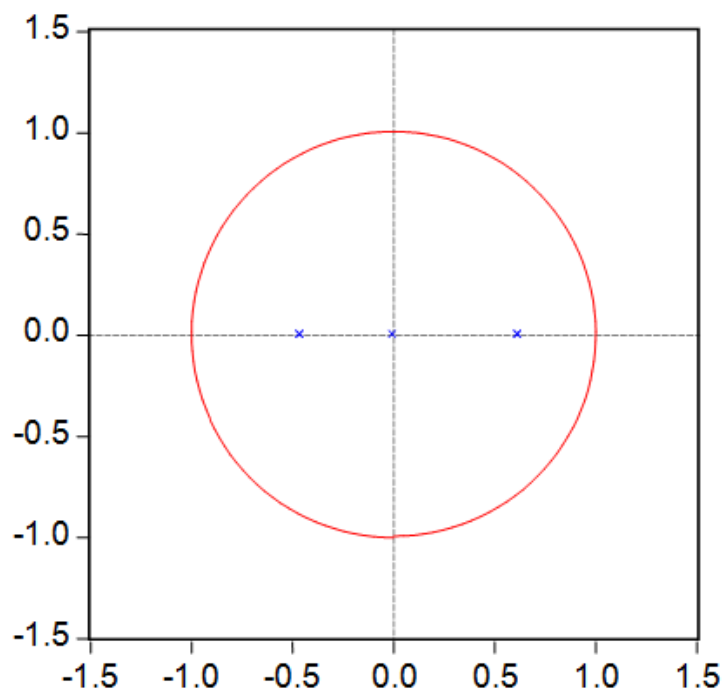

Fonte: Elaborado pelo pacote econométrico Eviews 5.0.

Na primeira coluna realiza-se um choque positivo na variável desemprego. Assim, para o primeiro gráfico, foi efetuado um choque de desemprego e uma consequente resposta do próprio desemprego, em que se pode observar uma elasticidade altamente positiva no primeiro mês e uma convergência absoluta logo no segundo mês, fato o qual revela uma suposta preocupação do Banco Central do Brasil com o nível de atividade econômica, evidenciando que a política monetária está em acordo com a meta de inflação estipulada. No segundo gráfico, tem-se um choque no desemprego e a resposta para o índice de preços para o mesmo, em que se percebe naturalmente uma elasticidade negativa até o sétimo mês. $\mathrm{E}$ para o caso de um choque no desemprego à taxa de juros, mantém-se uma elasticidade negativa até o terceiro mês, reforçando a hipótese de o $\mathrm{BCB}$ almeja atingir a meta de inflação. 


\section{FIGURA 3. FUNÇÕES DE RESPOSTA AO IMPULSO}

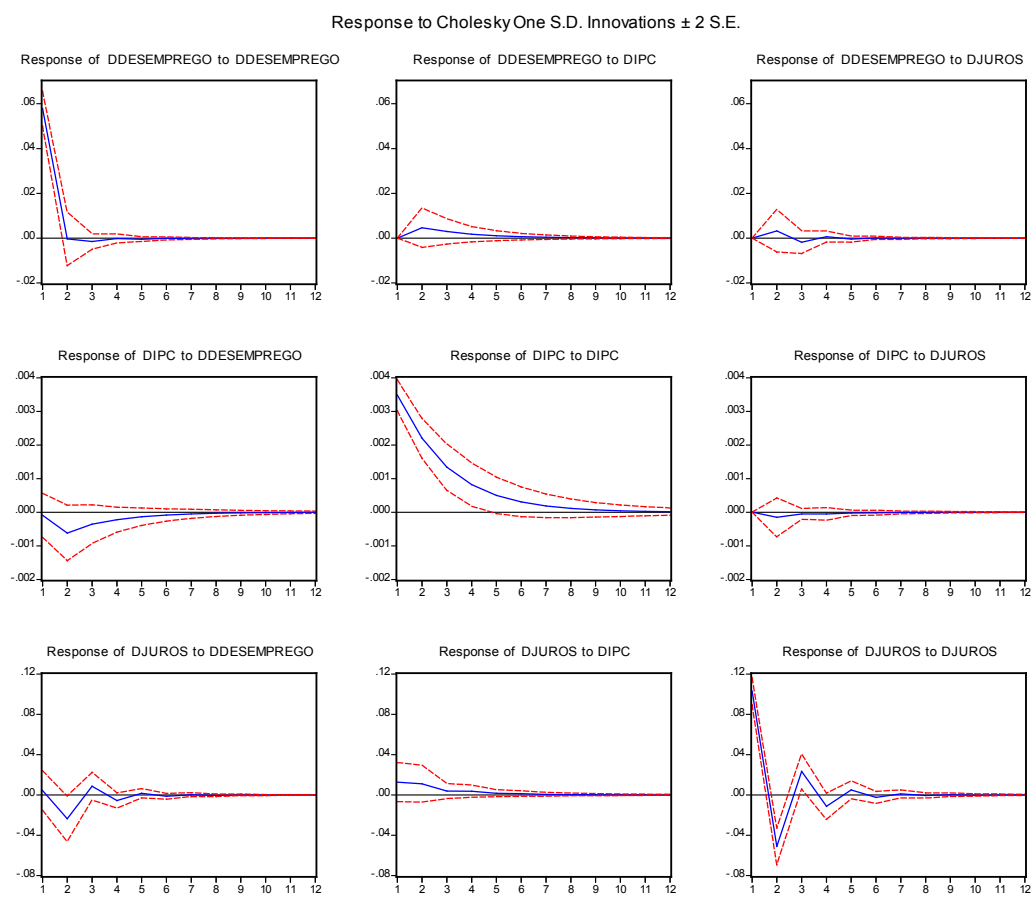

Fonte: Elaboração própria de acordo com cálculos do pacote Eviews 5.o.

Na segunda coluna observa-se um impacto originado por um choque externo na inflação e seus respectivos desdobramentos para as demais variáveis. A interpretação desta coluna será ordenada de forma diferente, começando pelo último choque (a resposta da taxa de juros pela inflação); nesse choque tem-se uma elevação na taxa de juros para conter o aumento de preços que, por conseguinte, acarreta em um aumento no desemprego (vide primeiro gráfico, resposta do desemprego pela inflação). E no caso da resposta da inflação pela própria inflação, verifica-se uma lenta convergência que ocorre no décimo mês.

Na terceira coluna, é ocasionado um choque nos juros para as demais variáveis. No primeiro gráfico, não surpreende, verificar uma elasticidade positiva no desemprego em relação a esse choque. Já no caso da inflação, observa-se uma branda diminuição inicial e uma integral convergência a partir do sexto mês, revelando que o período de defasagem da política monetária gira em torno de seis meses. Um choque nos juros pelos próprios juros ocasiona uma forte alta no primeiro mês e brusca diminuição que 
perdura até o segundo mês, convergindo a partir do sexto mês. Antes de passar para a análise do caso americano, cabe aqui ressaltar a semelhança entre os choques de reciprocidade entre as variáveis desemprego e juros (primeiro e último gráfico respectivamente da figura 3). $\mathrm{O}$ que se pode verificar nesses gráficos é que BCB procura atingir a meta, mesmo que tenha que reduzir a taxa de juros dada uma queda no nível de atividade econômica. Dessa forma, com base nos experimentos empíricos, observamos que o BCB tendo como o objetivo a meta de inflação, faz uso da política monetária. No caso da taxa de inflação estar acima da meta estipulada, o BCB aumenta a taxa de juros básica da economia, o que efetivamente exerce impacto sobre o desemprego, contudo caso a taxa de inflação estiver abaixo da meta estipulada, o BCB reduz a taxa de juros básica da economia.

\subsection{Estados Unidos - modelagem macroeconométrica}

O procedimento metodológico do modelo VAR para os EUA é análogo ao caso brasileiro. $\mathrm{O}$ teste de raiz unitária demonstrou que as três variáveis (desemprego, inflação e juros) eram não estacionárias, e portanto, houve necessidade da diferenciação das séries via primeira diferença do logaritmo. $\mathrm{O}$ resultado pode ser observado na Tabela 4.

TABELA 4. TESTE DE RAIZ UNITÁRIA DICKEY-FULLER AUMENTADO (ADF)

\begin{tabular}{lc}
\hline \multicolumn{2}{c}{$\begin{array}{c}\text { Null Hypothesis: D(DESEMPREGO) has a unit root } \\
\text { Exogenous: Constant, Linear Trend }\end{array}$} \\
\multicolumn{1}{c}{ Lag Length: 1 (Automatic based on SIC, MAXLAG=10) } \\
\hline & t-Statistic \\
Augmented Dickey-Fuller test statistic & -4.943 .958 \\
\hline Test critical values & -4.038 .365 \\
1\% level & -3.448 .681 \\
5\% level & -3.149 .521 \\
10\% level
\end{tabular}

Fonte: Elaboração própria de acordo com pacote Eviews 5.0. 
TABELA 4 (Continuação). TESTE DE RAIZ UNITÁRIA DICKEYFULLER AUMENTADO (ADF)

Null Hypothesis: D(IPC) has a unit root

Exogenous: Constant, Linear Trend

Lag Length: 2 (Automatic based on SIC, MAXLAG=10)

t-Statistic

Augmented Dickey-Fuller test statistic $\quad 9.634 .660$

Test critical values

$1 \%$ level

4.039.075

$5 \%$ level

3.449 .020

$10 \%$ level

3.149 .720

Null Hypothesis: D(JUROS) has a unit root

Exogenous: Constant, Linear Trend

Lag Length: 2 (Automatic based on SIC, MAXLAG=10)

t-Statistic

Augmented Dickey-Fuller test statistic $\quad 3.957 .786$

Test critical values

$1 \%$ level

4.039.075

$5 \%$ level

3.449 .020

$10 \%$ level

3.149 .720

Fonte: Elaboração própria de acordo com pacote Eviews 5.0.

A Figura 4 mostra as variáveis em nível e diferenciadas concomitantemente. As séries que obtinham tendências (linha vermelha) tiveram suas respectivas tendências removidas e passaram a serem estacionárias (linha azul). 
FIGURA 4. VARIÁVEIS EM NÍVEL E EM PRIMEIRA DIFERENÇA
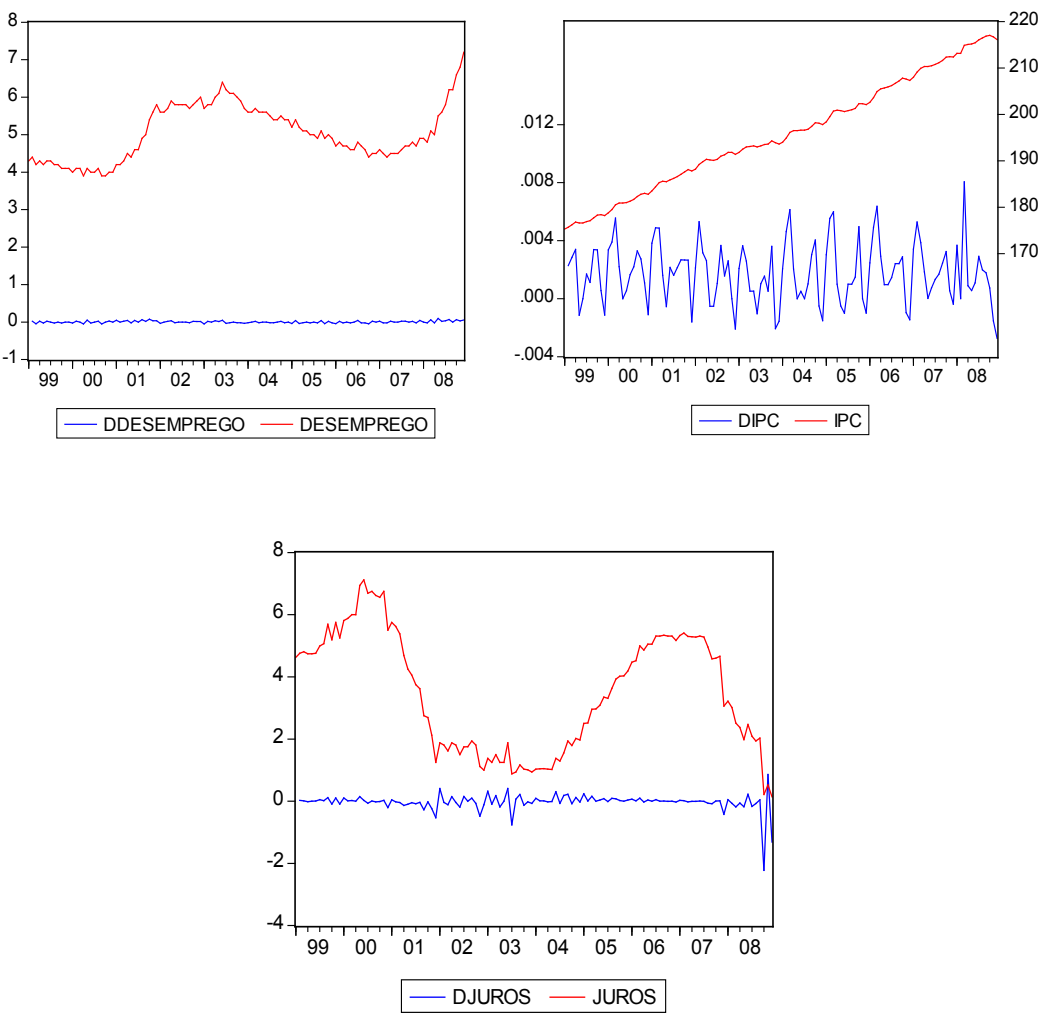

Fonte: Elaboração própria com base no pacote econométrico Eviews 5.o.

Os diversos critérios que foram utilizados para selecionar o melhor número de defasagens do modelo apontaram, como melhor opção três defasagens. Portanto, o modelo será realizado com as três variáveis diferenciadas e com três defasagens. O resultado está ilustrado na Tabela 4.5. 
TABELA 5. SELEÇÃO DO NÚMERO DE DEFASAGENS DO MODELO

\begin{tabular}{lllllll}
\hline Lag & LogL & LR & FPE & AIC & SC & HQ \\
\hline o & 727.64 & NA & $3.37 \mathrm{e}-10$ & -13.296 & -13.222 & -13.2662 \\
1 & 749.82 & 2.724 & $2.65 \mathrm{e}-10$ & -13.538 & -13.242 & -13.418 \\
2 & 774.33 & 5.866 & $1.99 \mathrm{e}-10$ & -13.822 & $-13.3041^{*}$ & -13.612 \\
3 & 792.61 & 33.213 & $1.68 \mathrm{e}-10^{*}$ & $-13.993^{*}$ & -13.252 & $-13.692^{*}$ \\
4 & 800.36 & 13.647 & $1.73 \mathrm{e}-10$ & -13.969 & -13.007 & -13.579 \\
5 & 810.09 & 16.609 & $1.71 \mathrm{e}-10$ & -13.983 & -12.798 & -13.503 \\
6 & 815.52 & 8.9688 & $1.83 \mathrm{e}-10$ & -13.918 & -12.511 & -13.347 \\
7 & 821.21 & 9.0838 & $1.96 \mathrm{e}-10$ & -13.857 & -12.227 & -13.196 \\
8 & 829.73 & 13.124 & $1.99 \mathrm{e}-10$ & -13.848 & -11.996 & -13.097 \\
9 & 841.74 & $17.858^{*}$ & $1.90 \mathrm{e}-10$ & -13.904 & -11.829 & -13.062 \\
10 & 849.99 & 11.803 & $1.96 \mathrm{e}-10$ & -13.889 & -11.593 & -12.958 \\
\hline
\end{tabular}

* indicates lag order selected by the criterion.

LR: sequential modified LR test statistic (each test at $5 \%$ level).

FPE: Final prediction error.

AIC: Akaike information criterion.

SC: Schwarz information criterion.

HQ: Hannan-Quinn information criterion

Fonte: Elaboração própria com base nos cálculos realizados no pacote econométrico Eviews 5 .

O teste de exogeneidade de Granger indicou a seguinte ordem para as variáveis: desemprego, inflação e juros. Coincidentemente o mesmo ordenamento para o caso brasileiro. Portanto, a Tabela 6 indica a ordem do modelo VAR.

TABELA 6. TESTE DE EXOGENEIDADE DAS VARIÁVEIS - VAR GRANGER CASALITY/BLOCK EXOGENEITY WALD TESTS

\begin{tabular}{llll}
\hline Dependent variable: & DDESEMPREGO & & \\
\hline Excluded & Chi-sq & DF & Prob. \\
DIPC & 4.652800 & 3 & 0.1991 \\
DJUROS & 2.255325 & 3 & 0.5211 \\
All & 6.276515 & 6 & 0.3929 \\
\hline
\end{tabular}

Fonte: Elaboração própria com base nos cálculos realizados no pacote econométrico Eviews 5. 
TABELA 6 (continuação). TESTE DE EXOGENEIDADE DAS VARIÁVEIS - VAR GRANGER CASALITY/BLOCK EXOGENEITY WALD TESTS

\begin{tabular}{llll}
\hline Dependent variable: DIPC & & \\
\hline Excluded & Chi-sq & DF & Prob. \\
DDESEMPREGO & 1.167490 & 3 & 0.7608 \\
DJUROS & 11.98979 & 3 & 0.0074 \\
All & 13.69707 & 6 & 0.0332 \\
\hline Dependent variable: DJUROS & & \\
\hline Excluded & Chi-sq & DF & Prob. \\
DDESEMPREGO & 15.13749 & 3 & 0.0017 \\
DIPC & 2.195434 & 3 & 0.5328 \\
All & 18.57823 & 6 & 0.0049 \\
\hline
\end{tabular}

Fonte: Elaboração própria com base nos cálculos realizados no pacote econométrico Eviews 5.

A análise das raízes inversas do polinômio característico auto-regressivo é fundamental nesse instante para verificar se há estabilidade no modelo. Como pode ser visto na Figura 5, é possível perceber que todas as raízes (como a maioria dos critérios indicaram três defasagens, há nove raízes) encontram-se dentro do círculo unitário, o que garante a estabilidade do modelo VAR.

A Figura 6 - função de resposta ao impulso - mostrará como as variáveis desemprego, inflação e juros se comportam diante de um choque. E subseqüentemente será realizada a análise da figura.

As funções de resposta ao impulso para o caso brasileiro foram verificadas na seção anterior, assim como uma pequena análise do cenário econômico à época. Agora far-se-á uma interpretação das funções impulso-resposta para o caso americano e - assim como no caso subjacente - uma breve análise conjuntural para a época. 
FIGURA 5. RAÍZES INVERSAS DO POLINÔMIO CARACTERÍSTICO AUTO-REGRESSIVO

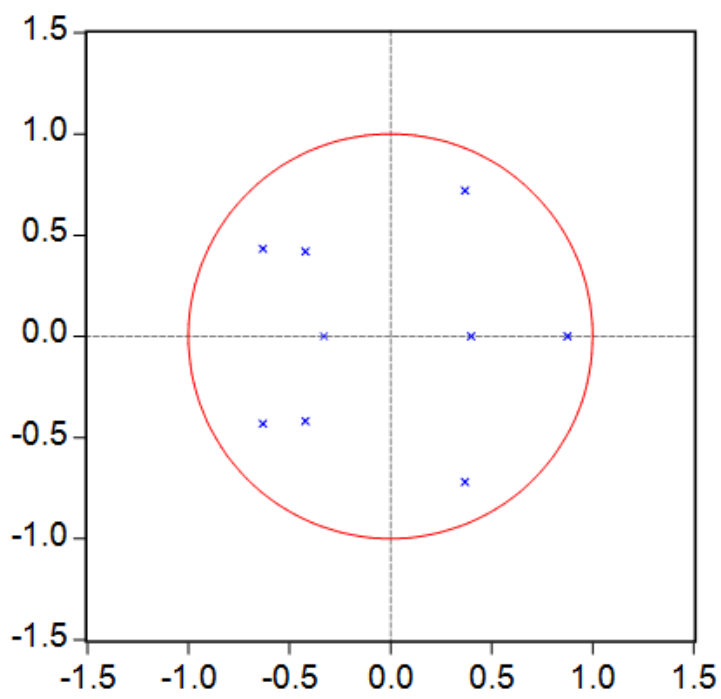

Fonte: Realizado no pacote econométrico Eviews 5.0.

A primeira coluna da figura 6 representa o comportamento das três variáveis em função de um choque exógeno positivo no desemprego. Observa-se para o caso de um choque no próprio desemprego, alta inicial e uma queda brusca que perdura até o segundo mês, reação análoga ao caso brasileiro. No segundo gráfico dessa coluna, verifica-se - não surpreendentemente - uma leve queda na inflação em detrimento do aumento no desemprego e consequente queda da demanda agregada. No último gráfico dessa coluna, percebe-se uma aversão do FED para com o desemprego, visto que a autoridade monetária americana historicamente pratica políticas monetárias expansionistas em épocas de queda na demanda agregada; diferentemente do Banco Central do Brasil, não é segredo que o FED almeja uma inflação controlada (com metas "implícitas") assim como um alto nível de emprego. 


\section{FIGURA 6. FUNÇÕES DE RESPOSTA AO IMPULSO}

Response to Cholesky One S.D. Innovations \pm 2 S.E.
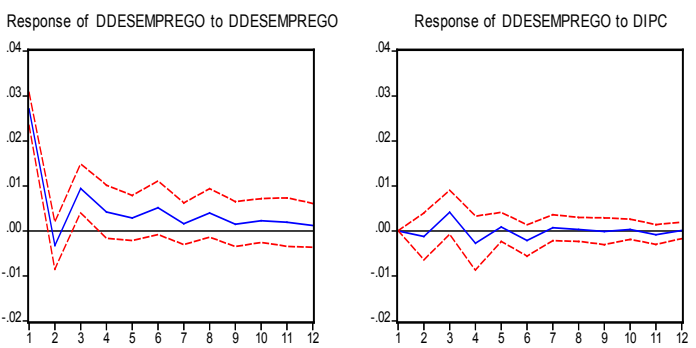

Response of DDESEMPREGO to DJUROS
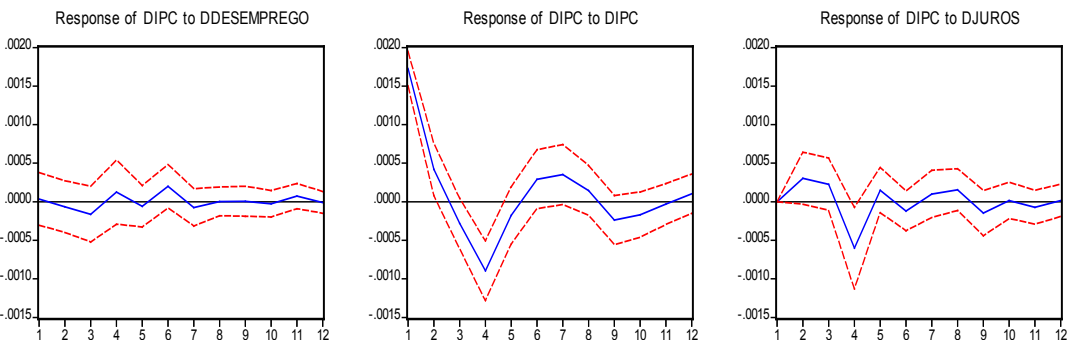

Response of DJUROS to DDESEMPREGO
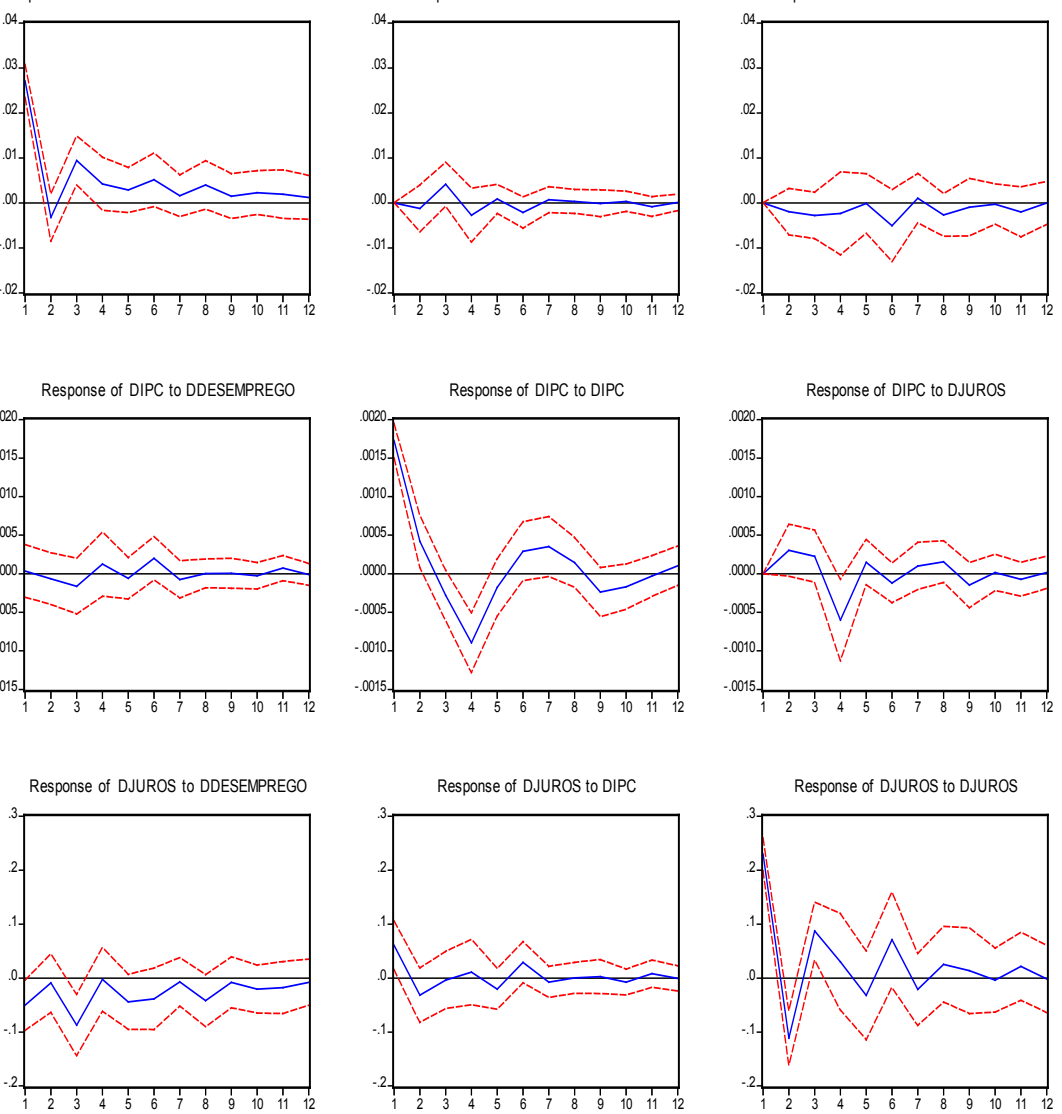

Fonte: Elaboração própria com base nos cálculos realizados no pacote Eviews 5.0.

Na segunda coluna, têm-se as respostas por um choque na inflação. Percebese baixa variância no desemprego com relação à inflação, só a partir do segundo mês tem um aumento na taxa de desemprego retorna no quinto mês ${ }^{16}$. Para o caso da inflação, verifica-se uma forte queda até o quarto

16 Percebe-se uma "conivência" maior com a inflação nos EUA do que no Brasil; cabe aqui dizer mais uma corroboração de uma economia trabalhando supostamente como o modelo novo-clássico, pois as expectativas ("racionais") dos agentes não se alteram (muito) diante de um aumento na inflação, não tornando assim, aventuroso o mercado de inversão no presente (que poderia ocasionar aumento do desemprego). Para o caso brasileiro o mesmo não se aplica integralmente, em razão de seu histórico na condução de problemas inerentes à inflação. 
mês e seguido de aumento até o sétimo mês e uma estabilização a partir de então. Os juros sobem no início, não obstante, demonstra uma elasticidade decrescente até o terceiro mês e convergência no período subseqüente.

Na terceira coluna, observam-se as funções de resposta ao impulso por um choque exógeno nos juros e como ele se propaga para as demais variáveis. Verifica-se que o instrumental monetário não tem grande significância para modificar o nível de emprego nos EUA, visto que só há uma pequena oscilação do mesmo entre o quinto e sexto mês. No segundo gráfico dessa coluna, analisa-se o período de defasagem da política monetária americana, a inflação não reduz até o terceiro mês, e só a partir daí que o índice de preços ao consumidor dá sinais de queda. Para o caso dos juros, percebe-se uma elasticidade altamente positiva no primeiro mês e uma acentuada queda que perdura até o segundo mês, e a partir de então, verifica-se uma relativa instabilidade monetária que só dá sinais de arrefecimento no décimo mês.

Ressalvando-se um importante fato, a política monetária americana, como se pode analisar na figura 4 - em que há o histórico dos juros -, teve fortes oscilações em razão do início de algumas crises, haja visto o período 2001 a 2004 e também a partir do segundo semestre de 2007, caracterizados por uma política monetária "frouxa" que visava minimizar os efeitos de um eventual aprofundamento dessas crises. Destarte, os preços dos FEDFUNDS traziam uma rentabilidade relativamente baixa - a despeito de sua credibilidade - e naturalmente fazendo a economia americana trabalhar com níveis baixos da taxa de juros. No entanto, essa política monetária sistemática suscita o aumento da "criatividade" no setor financeiro deixando o sistema econômico mais vulnerável a formação de "bolhas especulativas", assim, com o eventual estouro dessas "bolhas" e conseqüente deterioração das expectativas do mercado - em que haverá escassez de investimentos -, a economia americana não terá um mecanismo monetário preventivo eficaz anti-cíclico, a clássica queda na taxa de juros. Movimento esse já vivido pela economia japonesa na década de 1990, a qual tinha como característica recessão e concomitante deflação.

Assim, para a economia americana, a curva de Phillips de curto prazo também é valida, assim como no caso brasileiro.

\section{Considerações finais}

Após uma avaliação teórica do contexto econômico num mundo pósmercantilismo e suas consequentes vicissitudes até a etapa atual, o presente trabalho buscou em diversas fontes as origens dessas mudanças e o porquê 
das trocas de paradigmas econômicos. Observou-se que tais mudanças foram originadas pela dificuldade do modelo em questão de explicar o contexto econômico à época, mais especificamente, a dificuldade de se diagnosticar os ciclos econômicos. Analisou-se que os modelos econômicos que surgiram como "novas verdades" posteriormente foram substituídos - e de forma irretorquível - por uma "nova revolução" no modo de pensar em economia. Observou-se que as grandes mudanças econômicas dificilmente serão fenômenos idiossincráticos de cada nação, pelo contrário, para se entender essas mudanças é de vital importância a compreensão da geopolítica internacional.

Além desse estudo teórico abrangente, foi realizado também uma avaliação da conjuntura econômica no período 1999-2008 para o caso de Brasil e EUA. Verificou-se que a economia brasileira sofrera demasiadamente no período subjacente a estabilidade macroeconômica, e tal estabilidade era de fato necessária para aumentar a credibilidade (interna e externa) da economia nacional e facilitar (melhorar) sua inserção na rota de uma economia globalizada, cujo termo chave parece ser a credibilidade. Observouse também, que a economia americana trabalha para obter o objetivo (explícito), e fica sob a responsabilidade do FED atingi-lo: estabilidade de preços (metas implícitas).

Depois dessa explanação teórica, foi realizado uma modelagem macroeconométrica para verificar a eficácia de políticas monetárias de ambos os bancos centrais no período verificado. Os resultados mostraram que houve um aumento de fato da credibilidade do BCB, a possibilidade de um objetivo em sua agenda: inflação dentro da meta. Concluiu-se que, por mais que o BCB tenha uma postura austera, explorando o trade-off inflação/ desemprego da curva expectacional de curto prazo de Phillips, ele não é conivente com o aumento do desemprego. Cabe aqui uma explicação melhor, o que se verificou é que não há oportunismo no comportamento do BCB (devido a sua autonomia operacional) na melhor forma dos clássicos "ciclos políticos", visando tirar a economia da taxa natural de desemprego, mas sim uma preocupação com o nível de desemprego acima daquele em que as pessoas voluntariamente não querem trabalhar. O fato inaugura uma nova era da economia brasileira, em que movimentos internacionais adversos - que no passado recente eram encarados com uma política monetária contracionista - são minimizados pelo $\mathrm{BCB}$ via uma política monetária expansionista (queda na taxa de juros), fenômeno raro na história do país. 
Para o caso americano, concluiu-se também o objetivo na agenda do $\mathrm{FED}$, ressaltando sua maior aversão (com relação ao $\mathrm{BCB}$ ) a um baixo nível de atividade econômica. No entanto, a política sistematicamente laxista da autoridade monetária realmente minimizou os efeitos de crises inicias, porém, a persistência de tais políticas trouxeram uma taxa de juros exacerbadamente baixa e perda da eficácia de sua política monetária (via taxa de juros), destarte, para lidar com o fenômeno da crise atual, houve necessidade de emissão de papel moeda em escala jamais vista. Os desdobramentos dessa política são de difícil previsão, porém, espera-se que a economia americana não seja acometida por uma deflação e concomitante recessão, ou um caso tão perverso quanto, que é o de inflação e recessão simultaneamente, a clássica estagflação, fenômeno não impossível de acontecer depois de tamanha senhoriagem.

Dessa forma concluímos que a curva de Phillips de curto prazo, tanto para o Brasil quando para os Estados Unidos é valida ao menos no curto prazo, o que pode corroborar as hipóteses das teorias monetaristas, assim como as teorias das rigidezes dos salários para o caso da teoria novo-keynesiana.

\section{Referências bibliográficas}

AMORIM, R. L. C. (2002). "Macroeconomia neoclássica contemporânea: novoskeynesianos e novos-clássicos". Ensaios FEE, vol. 23, nº 1.

BLANCHARD, O. (2001). Macroeconomia. São Paulo: Pearson Prentice Hall.

BLINDER, A. S. (1998). Central Banking in Theory and Practice. USA: the MIT Press.

CARVALHO, F. et al. (2000). Economia Monetária e Financeira: Teoria e Prática. Rio de Janeiro; Campus.

CHRISTOPHER A. (1980). "SIMS - Macroeconomics and Reality". Econometrica. vol. 48, p. 1-48.

DEOS, S. S.; ANDRADE, R. (2006).” Metas de inflação: lições da era Greenspan". IE/UNICAMP, n. 121.

DILLARD, D. (1993). A Teoria Econômica de John Maynard Keynes: Teoria de uma Economia Monetária. São Paulo : Pioneira, Biblioteca Pioneira de Ciências Sociais.

FARHI, M. (2007). "Análise comparativa do regime de metas de inflação: passthrough, formatos e gestão nas economias emergentes". IE/UNICAMP, n. 127.

FROYEN, R. (2003). Macroeconomia. São Paulo: Saraiva.

GUJARATI, D. (2003). Econometria Básica. Rio de Janeiro: Elsevier.

HILLBRECHT, R. (2001). "Metas de Inflação e Política Fiscal". Revista Brasileira de Economia, vol. 55(3). 
IBGE - INSTITUTO BRASILEIRO DE GEOGRAFIA E ESTATÍSTICA. URL [on-line]: < http://www.ibge.gov.br/home/> Acesso em: jan. 2008.

JEVONS, W. S. (1983). A Teoria da Economia Política. São Paulo: Abril Cultural.

KEYNES, J. M. (1936). A teoria geral do emprego, do juro e da moeda. São Paulo: nova cultural.

Macrodados 7.o. URL [on-line]: < http://www.macrodadosonline.com.br > Acesso em: jan. 2008.

MODENESI, A. de M. (2005). Regimes Monetários: teoria e experiência do real. Barueri: Manole.

PHILLIPS, W. A. (1958). "The relation between unemployment and the rate of change of money wages in the United Kingdom, 1861-1957", Economica, v. 25.

KRUGMAN P. e OBSTFELD, M. (2010). Economia Internacional: Teoria e Política. São Paulo: Pearson Prentice Hall.

RODRIGUES, R. P. (2008). Socialismo no Século XX: o que deu errado? Goiânia: Kelps.

SICSÚ, J. (1996). A Tese de Independência do Banco Central e a Estabilidade de Preços: uma aplicação do método-Cukierman à história do FED. Rio de Janeiro: UFRJ.

SICSÚ, J. (2002). “Teoria e Evidência do Regime de Metas de Inflação”. Revista de Economia Política, vol. 22.

SIMONSEN, M. H.; CYSNE, R. P. (1995). Macroeconomia. São Paulo: Atlas.

SIMS, C. A. (1980). Macroeconomics and Reality. Econometrica. Vol. 48 (1).

SMITH, A. (2005). "An Inquiry into the Nature and Causes of the Wealth of Nations". In: SNOWDON, B.; VANE, H. R. Modern Macroeconomics: its origins, development and current state. Edward Elgar, Cheltenham.

SNOWDON, B.; HOWARD R. V. (2005). Modern Macroeconomics: its origins, development and current state. Edward Elgar, Cheltenham.

VARTANIAN, P. R. (2008). Choques monetários e cambiais sob regimes de câmbio flutuante nos países membros do Mercosul. São Paulo: PROLAM/USP.

VELOSO, J. P. (1998). “A fantasia política: a nova alternativa de interpretação do II PND”. Revista de Economia Política, vol. 18, nº 2 (70).

ZETTEL, A. P. F. V. (2006). A experiência de Chile, México e Brasil sob o regime de metas de inflação: uma comparação internacional. URL [on-line]: < http:// www.lume.ufrgs.br/handle/10183/10108>.

Recebido em: 24 de agosto de 2012

Aceito em: 29 de abril de 2013 